\title{
Driven to Support: Individual- and County-Level Factors Associated With Public Support for Active Transportation Policies
}

\author{
Angie L. Cradock, ScD', Jessica L. Barrett, MPH', Jamie F. Chriqui, PhD, MHS ${ }^{2}$, \\ Kelly R. Evenson, $\mathrm{PhD}, \mathrm{MS}^{3}$, Karin Valentine Goins, $\mathrm{MPH}^{4}$, Jeanette Gustat, $\mathrm{PhD}^{5}$, \\ Katie M. Heinrich, PhD ${ }^{6}$, Cynthia K. Perry, PhD, FNP ${ }^{7}$, Michele Scanze, MPH $^{8}$, \\ Thomas L. Schmid, PhD9, Rachel G. Tabak, PhD, RD ${ }^{10}$, \\ M. Renee Umstattd Meyer, PhD, MCHES ${ }^{\prime \prime}$, and Cheryl Valko, MPH, RD ${ }^{10}$
}

\begin{abstract}
Purpose: To assess predictors of stated support for policies promoting physically active transportation.

Design: Cross-sectional.

Setting: US counties selected on county-level physical activity and obesity health status.

Participants: Participants completing random-digit dialed telephone survey $(\mathrm{n}=906)$.
\end{abstract}

Measures: Survey measures assessed stated support for 5 policies to promote physically active transportation, access to active transportation facilities, and time spent in a car. County-level estimates included household car dependence and funding for bicycle-pedestrian projects.

Analysis: Multivariable generalized linear mixed models using binary distribution and logit link, accounting for clustering within county. Results: Respondents supported policies for accommodating bicyclists and pedestrians through street improvements (89\%), school active transportation programs (75\%), employer-funded active commuting incentives (67\%), and allocation of public funding (68\%) and tax support (56\%) for building and maintaining public transit. Residents spending $>2 \mathrm{~h} / \mathrm{d}$ (vs $<0.7 \mathrm{hours}$ ) in cars were more likely to support street (odds ratio [OR]: I.87; confidence interval [Cl]: I.09-3.22) and public transit (OR: I.85; Cl: I.24-2.77) improvements. Residents in counties investing $>\$ 1.6$ million in bicycle and pedestrian improvements expressed greater support for funding (OR: I.7I; Cl: I.04-2.83) and tax increases (OR: I.73; Cl: I.08-2.75) for transit improvements compared to those with lower prior investments $(<\$ 276$ I00).

Conclusion: Support for policies to enable active transportation is higher where relevant investments in active transportation infrastructure are large $(>\$ 1.6 \mathrm{M})$, public transit is nearby, and respondents drive $>2 \mathrm{~h} / \mathrm{d}$.

\section{Keywords}

physical activity, policy, active transportation, active tranpsort, public transit, car use, driving

\footnotetext{
' Department of Social and Behavioral Sciences, Harvard T. H. Chan School of Public Health, Boston, MA, USA

${ }^{2}$ Division of Health Policy and Administration, School of Public Health and the Institute for Health Research \& Policy, University of Illinois at Chicago, Chicago, IL, USA

${ }^{3}$ Department of Epidemiology, University of North Carolina at Chapel Hill, Chapel Hill, NC, USA

${ }^{4}$ Division of Preventive and Behavioral Medicine, University of Massachusetts Medical School, Worcester, MA, USA

${ }^{5}$ Department of Epidemiology; Prevention Research Center, Tulane University School of Public Health and Tropical Medicine, New Orleans, LA, USA

${ }^{6}$ Department of Kinesiology, Kansas State University, Manhattan, KS, USA

${ }^{7}$ Oregon Health \& Science University School of Nursing, Portland, OR, USA

${ }^{8}$ College of Architecture, Planning and Landscape Architecture, University of Arizona, Tucson, AZ, USA

${ }^{9}$ Physical Activity and Health Branch, Centers for Disease Control and Prevention, Atlanta, GA, USA

${ }^{10}$ Prevention Research Center, Brown School at Washington University in St Louis, St Louis, MO, USA

I' Department of Health, Human Performance, \& Recreation, Baylor University, Waco, TX, USA
}

Corresponding Author:

Angie L. Cradock, Department of Social and Behavioral Sciences, Harvard T. H. Chan School of Public Health, 7th Floor, 677 Huntington Avenue, Boston, MA 02II5, USA.

Email: acradock@hsph.harvard.edu 


\section{Purpose}

There is growing interest in designing communities to increase physical activity through everyday activities such as walking or bicycling for routine transportation. ${ }^{1}$ However, fewer than 1 in 5 US adults use physically active modes of transportation such as walking or bicycling at a level that is sufficient to meet minimum physical activity guidelines. ${ }^{2}$ Active travel, particularly over longer periods and distances, can have positive impacts on health and decreased disease risk. ${ }^{3,4}$ Transit use may also be considered a "physically active" transportation mode because the journey often involves walking or bicycling for a short distance at the beginning and end of a trip ${ }^{5}$ such that $29 \%$ of public transit users in the United States can accumulate 30 minutes or more of daily moderate physical activity during their transit commute. ${ }^{6}$ Physically active transportation happens most in settings with specific features. These include compact neighborhoods with mixed land use and proximal destinations; comprehensive networks for cycling, walking, and public transit; inviting and functional site designs for cyclists, pedestrians, and public transit users; and attributes that promote safety and accessibility. ${ }^{7,8}$ Efforts to create active transportation-friendly communities may also promote neighborhood interactions and social support for physical activity ${ }^{9}$ and benefit underserved areas, ${ }^{10}$ where active transportation infrastructure can be inadequate, unsafe, or in disrepair. ${ }^{11}$

Evidence suggests that community planning, zoning, and environmental changes to modify the physical infrastructure for active transport may facilitate changes in walking, cycling, and physical activity behaviors. ${ }^{7,8,11-13}$ Discourse on the development of healthy communities through local planning and community design is reflected in recent national recommendations, ${ }^{1,14}$ relevant health indicators, ${ }^{15,16}$ and public opinion. In Los Angeles County, voters reported that active transportation infrastructure investments were very important and also supported the redirection of transportation funding to enable improvements in amenities including sidewalks, bicycle lanes, and local bus and rail transportation. ${ }^{17}$ Such opinion research may inform local policy and planning efforts in communities and states and guide efforts at the national level as well.

This study uses existing data from an opinion survey conducted in counties selected based on levels of residents' selfreported physical activity and obesity status. We build upon related studies, ${ }^{18,19}$ adding data on prior local investments in active transportation infrastructure and household car dependence. We examine whether active transportation policy support differs by transportation behaviors, level of prior investments in bicycle and pedestrian projects, or current reported access to relevant resources for active transport.

\section{Methods}

\section{Study Design and Setting}

This study used a cross-sectional design to analyze individual-level data from a random-digit-dialed telephone survey conducted in 2011 among adults in selected US counties together with county-level data derived from the US Census Bureau, US Department of Agriculture (USDA) Economic Research Service, and the Federal Highway Administration (FHWA). Counties were selected in the survey administration protocol based on prior data on obesity and physical activity rates within the county. The protocol for this study was approved by the Harvard Chan School of Public Health Institutional Review Board.

\section{Sample}

All individual-level data used in this study were derived from the Physical Activity and Health Environments Policy Survey (PAHEPS), a random-digit-dialed telephone survey conducted among adults in selected US counties from August through November 2011. The PAHEPS was designed to understand patterns of support for policies influencing physical activity and characteristics predicting support for those policies. Counties in the highest and lowest tertiles for national population prevalence of both obesity and insufficient activity were selected for the sampling frame to elicit variability in survey responses. Response rates across county strata sampled ranged from $38 \%$ to $46 \%$ for landline households and $9 \%$ to $27 \%$ for cellular phones. ${ }^{18}$ Surveys were conducted among 1218 adults aged 18 years and older sampled from 884 US counties with a high prevalence of adults with obesity and insufficient physical activity and 171 US counties with a low prevalence of obesity and insufficient physical activity. Disproportionate numbers of counties in each of these categories were sampled to achieve a minimum response rate in each category. Prevalence estimates of obesity and insufficient physical activity used to define the sampling frame were estimated using information from the US Census and the Behavioral Risk Factor Surveillance System (BRFSS), as summarized in data available from the Centers for Disease Control and Prevention (CDC). ${ }^{20}$ Obesity was defined as having a body mass index (BMI) of $30 \mathrm{~kg} / \mathrm{m}^{2}$ or higher, according to self-reported height and weight. Insufficient activity was defined as self-reporting not meeting national recommendations for physical activity of either $\geq 150$ minutes of moderate activity or $\geq 75$ minutes of vigorous activity per week or equivalent of the 2 combined. ${ }^{21}$ In this study, we define county obesity and physical activity category as "more healthy" for counties in the lowest tertiles for the prevalence of obesity and insufficient activity and as "less healthy" for counties in the highest tertiles for the prevalence of obesity and insufficient activity.

\section{Survey}

The survey was developed by the Prevention Research Center in St Louis and the Physical Activity Policy Research Network (PAPRN) to understand patterns of support for policies influencing physical activity. The CDC Prevention Research Centers Program created the PAPRN in October 2004 to study the effectiveness of health policies related to increasing physical activity in communities. The survey, 
which consisted of 74 questions in 8 sections, was fielded by Clearwater Research, Inc. Additional details of the survey design and sampling and data collection procedures are described elsewhere. ${ }^{18}$ The survey protocol was approved by the Washington University in St Louis Institutional Review Board.

\section{Measures}

Policy support outcomes. The opinion survey included 5 questions to assess support for active transportation policies based on an existing instrument. ${ }^{22}$ Participants were asked whether (1) cities should be required to accommodate pedestrians and bicyclists when street improvements are made, (2) they support funding for programs encouraging walking and bicycling to school, (3) employers should provide incentives for active commuting to work, (4) their city should allocate funds for building and maintaining public transit, and (5) they support a tax increase for building or maintaining public transit in their community. Respondents indicated "yes" or "no" to each question.

Individual level predictors. Transportation habits were assessed by hours spent in a car on a usual weekday $(<0.7$ hours, 0.71.9 hours, or $2+$ hours, based on tertiles of observed responses). Perceptions of active transportation facilities in the neighborhood environment were assessed by agreement or disagreement on a 4-point Likert-type scale (strongly disagree, somewhat disagree, somewhat agree, and strongly agree) with statements indicating (1) transit within a 10 to 15 walk from home, (2) sidewalks on most neighborhood streets, and (3) facilities to bicycle in or near the neighborhood. These items were derived or modified for use from an existing survey instrument. ${ }^{23}$ Other individual-level covariates included survey respondents' self-reported characteristics of sex, age category, race/ethnicity, education attained, employment status (employed or unemployed), BMI category, and physical activity behavior, which researchers theorized were related to preferences and transportation-related behaviors. Body mass index category was coded as under/ normal weight $\left(<25 \mathrm{~kg} / \mathrm{m}^{2}\right)$, overweight $\left(25-29.9 \mathrm{~kg} / \mathrm{m}^{2}\right)$, or obese $\left(30+\mathrm{kg} / \mathrm{m}^{2}\right)$ based on self-reported height and weight. ${ }^{24}$ Physical activity behavior was coded as meeting or not meeting national recommendations for physical activity of 150 minutes of moderate activity, 75 minutes of vigorous activity, or the equivalent combination per week, ${ }^{21}$ according to self-reported times per week and hours and minutes per time spent in moderate and vigorous activity separately per the BRFSS protocol in 2009. ${ }^{24}$ National estimates for demographic characteristics collected in the survey were obtained from the 2007 to 2011 American Community Survey, ${ }^{25}$ the 2010 US Census, ${ }^{26}$ and the 2009 BRFSS $^{24}$ to compare the representativeness of the survey sample. No comparative national estimates were available for questions related to transportation habits and neighborhood environment perceptions.
County-level predictors. County-level variables of interest included county-level obesity and physical activity status, urban/rural status, household car dependence, household income, and federal funds obligated for bicycle and pedestrian projects. The county-level obesity and physical activity category was defined as "more healthy" or "less healthy" by tertile according to the survey sampling process as noted earlier. The USDA Economic Research Service 2013 Urban Influence $\mathrm{Codes}^{27}$ were used to assign urban/rural status to each county: "urban" counties were defined as counties in large metro areas of 1 million or more residents, small metro areas of $<1$ million residents, or micropolitan areas; and "rural" counties were defined as counties not located in metro or micropolitan areas ("noncore"). The 2007 to 2011 American Community Survey 5 -year estimates from the US Census Bureau ${ }^{25}$ were used to describe household car dependence and household income. As in prior studies, the automobile dependency level was assessed based on the household car ownership level expressed as the percentage of households in the county owning 2 or more vehicles. ${ }^{28}$ The Financial Management Information System (FMIS) of the FHWA ${ }^{28}$ was used to describe federal funds obligated in each county for bicycle and pedestrian projects. The FHWA FMIS database tracks transportation project financial information including the date of funding obligation, state and county of project location, and type of project. Annual federal funds obligated for bicycle and pedestrian projects during the years 1992 to 2011 were standardized to 2011 US dollars using the consumer price index. Total funds obligated during that period were categorized in tertiles based on observed data $(\$ 276.1$ thousand or less, $>\$ 276.1$ thousand to $\$ 1.6$ million, or $>\$ 1.6$ million).

\section{Analysis}

The analytic sample for this study was 906 adults aged 18 years and older who provided responses to all survey variables of interest ( $74 \%$ of the 1218 respondents). Compared to respondents included in the analysis $(\mathrm{n}=906)$, respondents excluded from the analysis $(\mathrm{n}=312)$ were significantly more likely to be female, older, and unemployed. Respondents were less likely to meet moderate or vigorous physical activity recommendations, report having a transit stop in the neighborhood, report having facilities to bicycle in or near the neighborhood, support employers providing incentives for actively commuting to work, and support a tax increase for building or maintaining public transit in the community $(P<.05$ for each comparison; data not shown). There were no differences between included and excluded respondents for other variables of interest.

Descriptive statistics for all individual- and county-level variables of interest was calculated overall and by county obesity and physical activity category ("more healthy" and "less healthy"). Differences between "more healthy" and "less healthy" counties were assessed using $\chi^{2}$ or $t$ tests for each predictor variable. Differences in the likelihood of active transportation policy support for each outcome according to county 
obesity and physical activity status were estimated by an unadjusted generalized linear mixed model with a binary distribution and logit link, accounting for clustering of individuals within counties. Associations between all individual- and county-level characteristics and reported support for active transportation policies were assessed using multivariable generalized linear mixed models with a binary distribution and logit link, accounting for clustering of individuals within counties. Separate models were fit for each of the 5 policy support outcomes. Each fully adjusted model included county-level variables and individual-level car use and perceptions of active transportation facilities in the neighborhood environment as primary predictors of interest, adjusting for individual-level characteristics hypothesized to relate to preferences and transportation-related behaviors. All analyses were conducted using SAS version 9.4 (SAS Institute, Inc, Cary, North Carolina). All analyses were performed using unweighted data given the lack of large sample size and inability to generalize to the national US population. ${ }^{29}$

\section{Results}

Table 1 depicts the demographic characteristics, health risk factors, car use, and perception of neighborhood active transportation supports overall and by county-level obesity and physical activity category. Respondents in "more healthy" and "less healthy" counties were similar with respect to sex, age, and race/ethnicity, but "more healthy" counties had higher percentages of college-educated and employed respondents, and, as expected, more respondents meeting physical activity requirements and fewer with obesity. While similar proportions of respondents reported spending 2 or more hours in a car on a usual weekday in "more healthy" and "less healthy" counties, the proportions agreeing that they had access to local infrastructure supporting physically active transportation choices were greater among "more healthy" than "less healthy" county residents for access to transit within a 10 -minute walk ( $52 \%$ vs $17 \%, P<.001)$, amenities such as sidewalks ( $54 \%$ vs $32 \%, P<.001)$, or bicycling lanes/ paths $(66 \%$ vs $26 \%, P<.001)$. As shown in Table 2, "more healthy" and "less healthy" counties differed on all countylevel variables of interest except automobile dependence. Compared to "less healthy" counties, "more healthy" counties had higher reported average household income (\$59158 vs $\$ 37824)$, were more likely to be urban ( $73 \%$ vs $47 \%$ ), and were more likely to have investments in bicycle and pedestrian projects from 1992 to 2011 that totaled at least $\$ 1.6$ million ( $72 \%$ vs $19 \%$; all comparisons $P<.001)$.

Overall, the majority of survey respondents supported policies for accommodating bicyclists and pedestrians in street improvements (89\%), active school transportation programs (75\%), employer-funded active commuting incentives (67\%), allocation of public funding (67\%), and tax support for building and maintaining public transit (55\%; Table 3). Support for active school transportation program funding (odds ratio [OR]: $2.08 ; 95 \%$ confidence interval [CI]: 1.51-2.87), employee incentives for active commuting (OR: 1.65; $95 \%$ CI: 1.25-2.19), allocating funds for building and maintaining transit (OR: 2.37; 95\% CI: 1.71-3.29), and supporting a tax increase to build or maintain public transit (OR: 1.81; $95 \%$ CI: 1.36-2.41) was significantly greater among residents of "more healthy" counties compared to residents in "less healthy" counties. Support for requiring cities to accommodate pedestrians and bicyclists when roadway improvements were made did not differ by county obesity and physical activity status category.

After adjusting for individual- and county-level study covariates, residents living in "more healthy" counties were only more likely to support programs that encourage walking and bicycling to school (OR: 1.93; CI: 1.19-3.13) than those in "less healthy" counties (Table 4). Residents who lived within a short walk to public transit (agree vs disagree) were more likely to support funds for building or maintaining public transit (OR: 2.74; CI: 1.74-4.30) and tax increases for public transit (OR: 1.89; CI: 1.29-2.77). Similarly, residents who agreed that there were facilities to bicycle in or near their neighborhood were marginally more likely to support employer incentives for active commuting (OR: 1.40; CI: 0.99-1.98). Both respondent-reported car use and countylevel measures of automobile dependence were related to reported support for some active transportation policies. Spending 2 or more hours per day in a car, compared to spending less than 0.7 hours per day in a car, was associated with increased odds of reported support for accommodating bicycles and pedestrians in street improvements (OR: 1.87; CI: 1.09-3.22) and support for funds for building or maintaining public transit (OR: 1.85; CI: 1.24-2.77), independent of individual- and county-level characteristics. Residents in counties with greater automobile dependence were less likely to support funding for programs supporting active school transportation or transit. With each point increase in the proportion of households with 2 or more vehicles, there was a significant decrease in the odds of supporting funding for children's active transportation to school (OR: 0.97; CI: $0.95-1.00)$ and building or maintaining public transit (OR: 0.97; CI: 0.95-1.00). However, independent of other individual covariates, living in a county with greater levels of prior investment in the community's bicycle and pedestrian infrastructure and programs (investments from 1992-2011 totaling $\$ 1.6$ million or more vs $\$ 276100$ or less) was associated with greater support for policies supporting public transit (OR: 1.71; CI: 1.04-2.83) and public transit tax funding (OR: 1.73; CI: 1.08-2.75).

\section{Discussion}

In the population studied, the majority of respondents reported support for policies to facilitate active transportation. However, support for some policies varied according to the level of prior investment in the community's pedestrian and bicycle infrastructure and programming, self-reported access to local active transportation-related amenities such as bicycle facilities or 
Table I. Sociodemographic Characteristics, Transportation Habits, and Neighborhood Environment Perceptions of Survey Respondents.

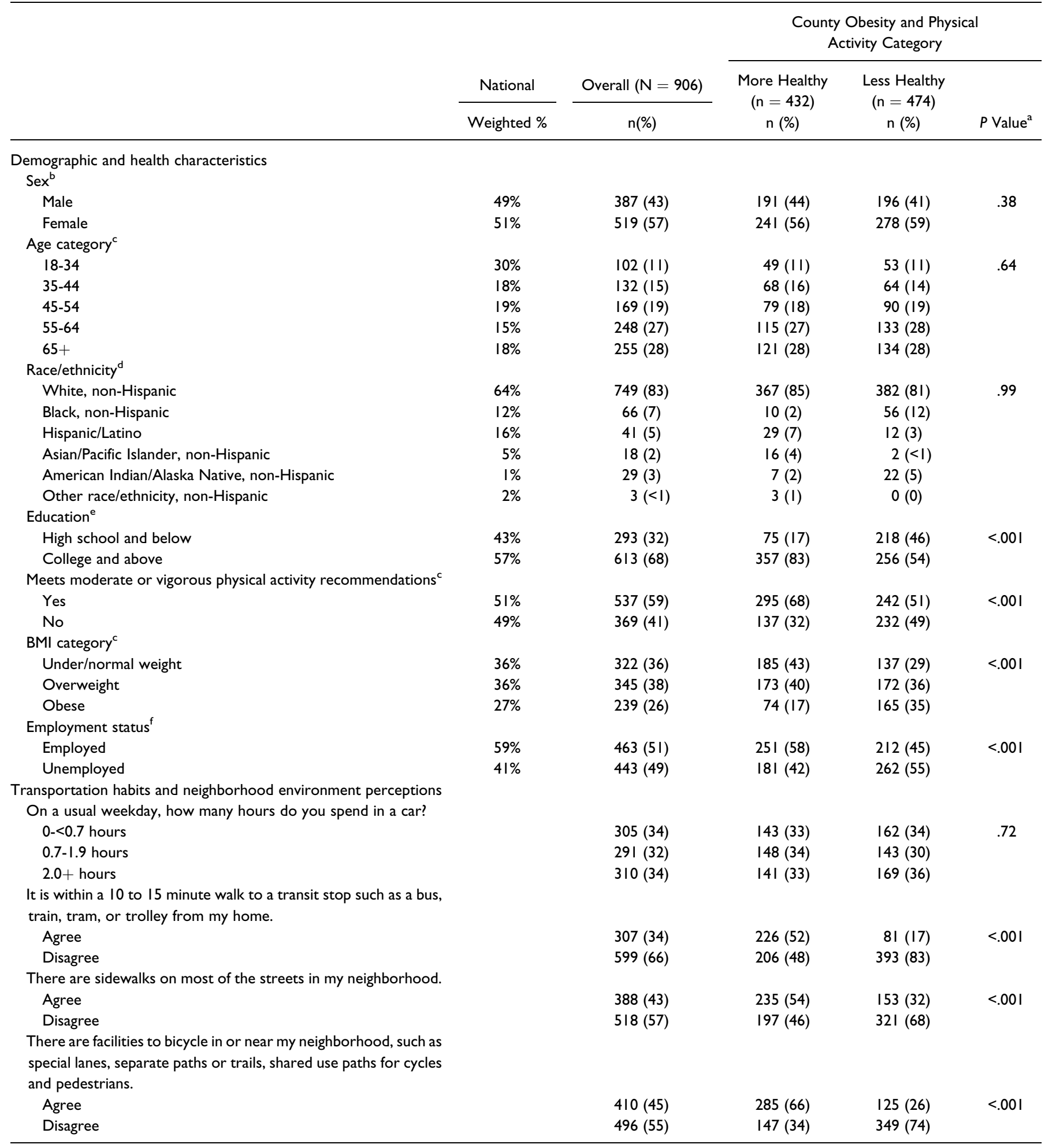

Abbreviations: ACS, American Community Survey, BMI, body mass index; BRFSS, Behavioral Risk Factor Surveillance System.

${ }^{a}$ Statistical significance was assessed using $\chi^{2}$ analysis. The Mantel-Haenszel w2 test was used for characteristics with more than 2 categories.

bNational estimates taken from the 2007 to 201 I ACS data.

'National estimates taken from the BRFSS 2009 data.

dNational estimates for race/ethnicity are taken from the 2010 US Census.

eNational estimates for Educational Attainment are taken from the 2007 to 20 II ACS data, population 25 years and over.

f National estimates for Employment Status are taken from the 2007 to 201 I ACS data, population 16 years and over. 
Table 2. Geographic and Demographic Characteristics and Federal Bicycle and Pedestrian Funding Levels of Counties in Which Survey Respondents Reside.

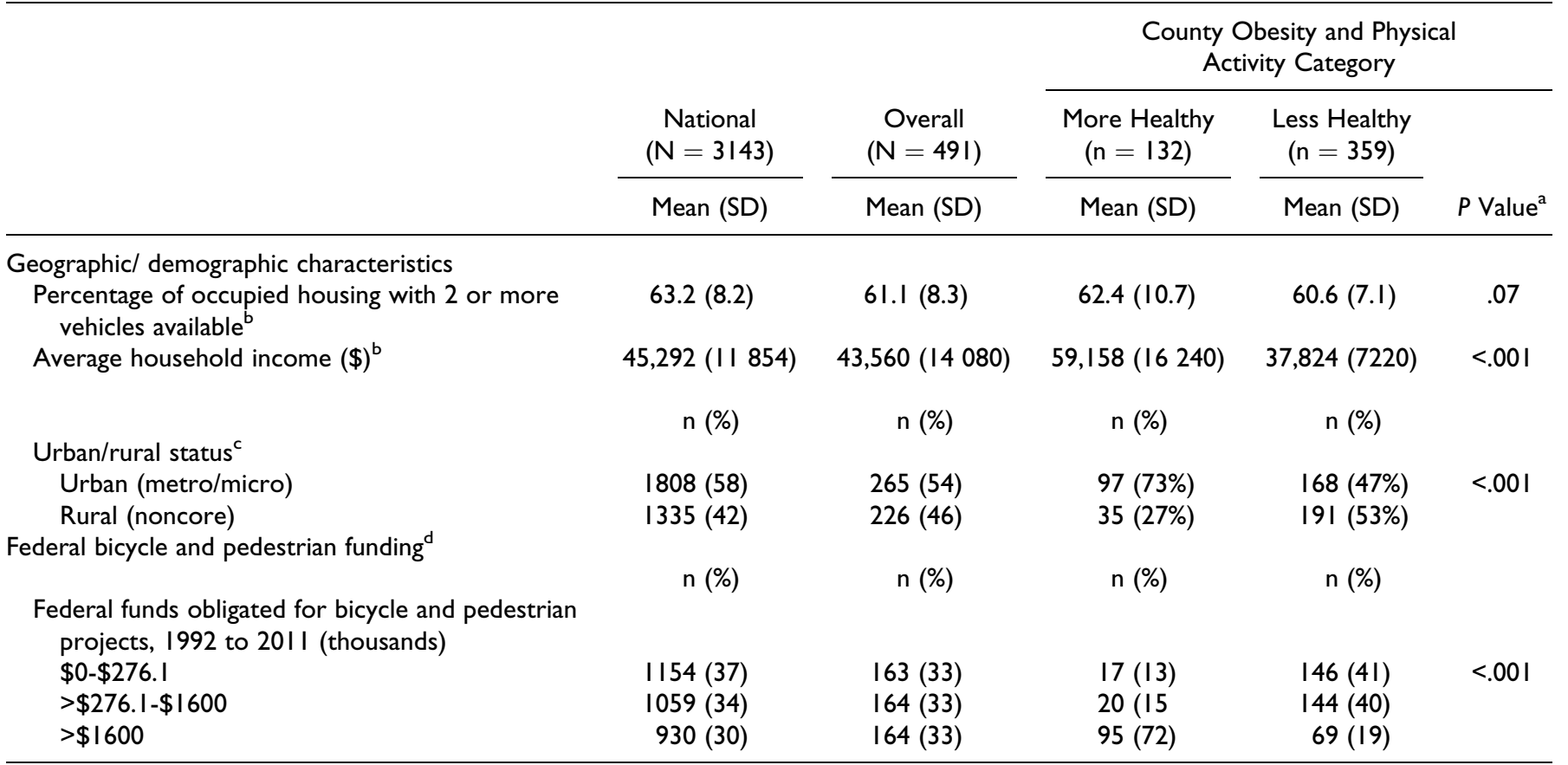

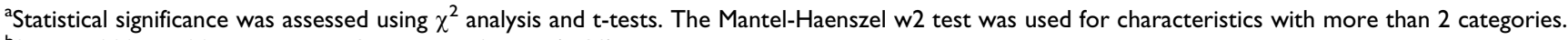
bSource: 2007 to 201 I American Community Survey (ACS) data.

'National estimates for urban/rural status are taken from 2013 urban influence codes, US Department of Agriculture (USDA) Economic Research Service.

dSource: Fiscal Management Information System (FMIS), Federal Highway Administration

transit stops, time spent in a car each day, and county-level household car access. Notably, federally funded resource investment in bicycling and pedestrian improvements and programs supporting active transportation implemented in the 20 years prior to the study was higher in those counties with better obesity-related health-risk profiles. Seventy-two percent of the counties with a high prevalence of healthy BMI status and physical activity patterns fell into the highest category of investment for active transport investment during the prior 2 decades. Among the counties with a high prevalence of insufficient activity and obesity, fewer than 1 in 5 counties had the highest levels of capital investments in projects for pedestrians and bicyclists in the 20 years prior to the survey. The association between existing local features, transportation patterns and preferences, and health has been observed at various geographic scales. Using international, state, and city data available on active transportation and physical activity, obesity, and diabetes, Pucher and colleagues ${ }^{30}$ documented significant associations between active travel and health that were discernible at each geographic level.

Although areas with urban sprawl and car-focused travel patterns are associated with adverse effects on public health and the environment, policy strategies designed to counter sprawl have been controversial and difficult to implement in some instances. ${ }^{31}$ These difficulties may arise from a lack of supportive public opinion or local cultural norms. In this study, support for funding transit and programs that enable active transport to school was lower among residents living in counties with higher proportions of households with 2 or more cars, where presumably travel in a vehicle may be a preference and cultural norm. Nationally, two-thirds of the public agreed that funding for transit should be at least proportional to the share of commuters using the mode. ${ }^{32}$ Similarly, in this study, the majority of survey respondents supported the allocation of public funding (68\%) and tax support (56\%) for building and maintaining public transit, and support was significantly higher among those respondents also reporting access to a transit stop within a 10- or 15-minute walk from their home.

These results suggest that locally, public support may differ according to individual and collective experience. It is possible that greater access to amenities for physically active transportation prompts use and increased demand for better facilities. Communities interested in promoting policy and investment to make physically active transportation easier may want to focus on pilot initiatives within local areas to document changes in public opinion, as residents gain more personal experience with such amenities and options. This feedback mechanism is supported by other research, where the development of more favorable opinions over time for bicycle sharing and access programs differed according to personal exposure and access to bicycles and bicycling amenities as part of a public bicycle share program. ${ }^{33}$ Residents who used the bicycle facilities and reported access to bicycle sharing amenities developed more favorable opinions of these options over time. This finding raises the possibility that inequalities or limited investment in facilities and programs that enable active transport may further 
Table 3. Support for Active Transportation Policies Among Public Perceptions Survey Respondents, 20 II.

\begin{tabular}{|c|c|c|c|c|c|}
\hline & \multirow{2}{*}{$\begin{array}{c}\begin{array}{c}\text { Overall } \\
(\mathrm{N}=906)\end{array} \\
n(\%)\end{array}$} & \multicolumn{4}{|c|}{ County Obesity and Physical Activity Category } \\
\hline & & $\begin{array}{l}\text { More Healthy } \\
\qquad(n=432) \\
n(\%)\end{array}$ & $\begin{array}{l}\text { Less Healthy } \\
(n=474) \\
n(\%)\end{array}$ & OR $(95 \% \mathrm{Cl})^{\mathrm{a}}$ & $P$ Value \\
\hline \multicolumn{6}{|c|}{$\begin{array}{l}\text { Should cities be required to accommodate pedestrians and } \\
\text { bicyclists when improvements to streets are made? }\end{array}$} \\
\hline \multicolumn{6}{|c|}{$\begin{array}{l}\text { Do you support funding for programs that encourage } \\
\text { walking and bicycling to school? }\end{array}$} \\
\hline Yes & $677(75)$ & $353(82)$ & $324(68)$ & $2.08(1.51-2.87)$ & $<.001$ \\
\hline No & $229(25)$ & $79(18)$ & $150(32)$ & & \\
\hline \multicolumn{6}{|c|}{$\begin{array}{l}\text { Do you think employers should provide incentives for } \\
\text { actively commuting to work? }\end{array}$} \\
\hline \multicolumn{6}{|c|}{$\begin{array}{l}\text { Do you think your city should allocate funds for building } \\
\text { or maintaining public transit? }\end{array}$} \\
\hline Yes & $619(67)$ & $335(78)$ & $284(60)$ & $2.37(1.7 I-3.29)$ & $<.001$ \\
\hline No & $287(33)$ & $97(22)$ & $190(40)$ & & \\
\hline \multicolumn{6}{|c|}{$\begin{array}{l}\text { Would you support a tax increase in your city for building } \\
\text { or maintaining public transit in your community? }\end{array}$} \\
\hline Yes & $504(55)$ & $273(63)$ & $231(49)$ & $\mathrm{I} .8 \mathrm{I}(\mathrm{I} .36-2.4 \mathrm{I})$ & $<.001$ \\
\hline No & $402(45)$ & $159(37)$ & $243(5 I)$ & & \\
\hline
\end{tabular}

Abbreviations: $\mathrm{Cl}$, confidence interval; OR, odds ratio.

${ }^{a}$ Odds ratios were calculated for the unadjusted difference by county obesity and physical activity category using generalized linear mixed models with a binary distribution and logit link, accounting for clustering of individuals within counties.

exacerbate unequal access because public support has not developed because residents have had no experience or exposure to quality active transportation amenities.

Decision-makers consider the opinions of their constituents when developing their priority policies. ${ }^{34}$ However, building a supportive transportation structure that includes administrative priorities, available resources, and implementation targets supportive of bicyclists and pedestrians in the United States has taken time. For example, in 2010, just 6 states had spending targets for projects supporting bicycling and walking, and only half of US states had developed a bicycle and/or pedestrian plan to guide such improvements. However, 6 years later, 15 states had determined spending targets for active transport, and 34 states had developed plans to guide investments. ${ }^{35}$ Meanwhile, the implementation of policy and systems strategies to change the physical infrastructure to promote walking and bicycling must often occur at various levels of government. Certain policies may necessitate the collaboration between multiple departments within a single level of government and may require coordination across jurisdictions. These complexities in collaboration, coordination, and jurisdictions can also create potential roadblocks, independent of the level of public support for such policy or programmatic initiatives. ${ }^{36}$

This study uses a cross-sectional design and therefore precludes assessment of causal associations or the potential impact of residential self-selection. Additionally, the sample was not nationally representative but rather purposefully selected from counties based on higher or lower levels of county-level population health-related risk factors of obesity and insufficient activity known to be associated with active transportation behaviors. The survey response rate was relatively low, and $26 \%$ of respondents were excluded from this analysis due to nonresponse on survey items of interest, further limiting the generalizability of results. Although we accounted for urban and rural status, our measure of 20 years of prior investment in bicycle and pedestrian infrastructure and programs does not account fully for differences in county population nor other potential sources of local or state funding for bicycle and pedestrian improvements. Additionally, we did not enquire about length of residence in the county, and residential relocation to counties with more amenities may be related to physical activity or obesity status and stated policy support. All data from individuals are self-reported, with potential for respondent reporting error. Strategies used for classification of county-level and individual-level variables are based on the sample population responses or question format; thus, categories may obscure associations that might be observed using other categorizations or data modeling strategies. ${ }^{37}$

This study describes support for several active transportation-related policies and variability in support by individual and local county characteristics that include the presence of supportive physical infrastructure and access to amenities. Support for policies to enable active transport is 


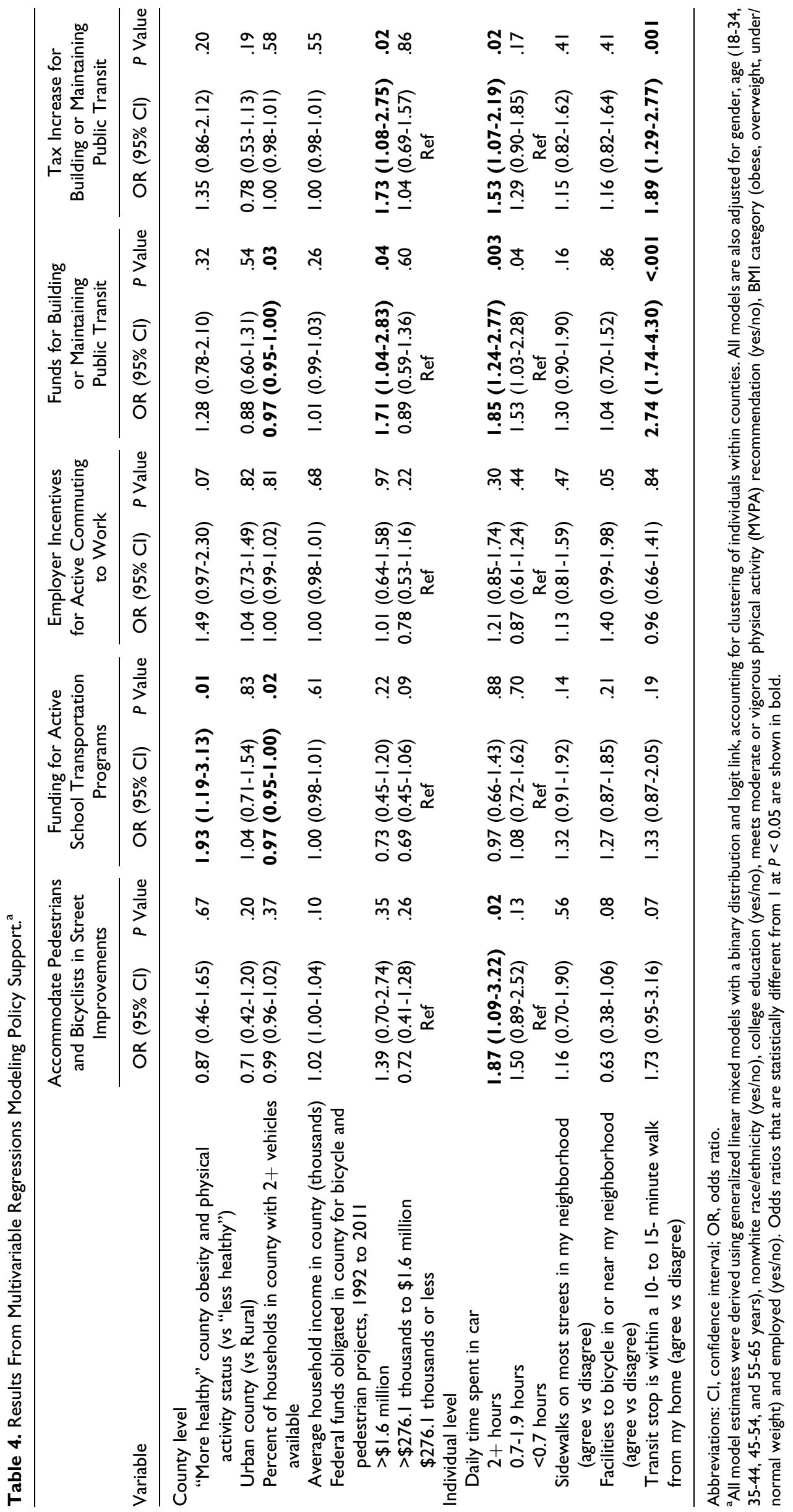




\section{SO WHAT?}

\section{What is already known about this topic?}

Walking and bicycling for transportation can contribute to health. Community planning, zoning, and environmental changes to modify the physical infrastructure for active transportation may facilitate changes in walking, cycling, and other physically activity transport behaviors such as public transit use. Supportive environments can be created by decision-makers who also value the needs and opinions of their constituents when determining their priority policies.

\section{What does this article add?}

We have built upon related studies of public support for policy that promotes physically active transportation by including data on 20 years of local investments in active transportation infrastructure and county-level household car dependence. We found that support for policies to enable active transportation is higher where relevant investments in active transportation infrastructure are large $(>\$ 1.6 \mathrm{M})$, public transit is nearby, and respondents drive $\geq 2 \mathrm{~h} / \mathrm{d}$.

\section{What are the implications for health promotion practice or research?}

These results suggest that, locally, public support for policies that can promote active transportation may differ according to individual and collective experience. It is possible that greater access to amenities for physically active transportation prompts use and increased demand for better facilities. Communities interested in promoting policy and investment to make physically active transportation easier may want to focus on initiatives within local areas to foster more personal experience with amenities and options.

high, and for some policies was higher with greater prior economic investment in facilities and programs promoting active transport, better access to local active transportation-related amenities, and when respondents spent $2+\mathrm{h} / \mathrm{d}$ in a car.

\section{Authors' Note}

The findings and conclusions in this report are those of the authors and do not necessarily represent the official position of the CDC.

\section{Authors' Contributions}

All authors approved the version of the manuscript submitted for publication and participated sufficiently in the work to take public responsibility for appropriate portions of the content. Angie L. Cradock developed the study concept and oversaw design, provided input into survey questions, led acquisition and analysis of data, provided interpretation of data, and drafted the manuscript and revised it critically for important intellectual content. Jessica L. Barrett provided input into study design, provided analysis and interpretation of data, and drafted portions of the manuscript and revised it critically for important intellectual content. Jamie F. Chriqui provided input into survey questions and study design, contributed to acquisition of data, provided interpretation of data, and revised the manuscript critically for important intellectual content. Kelly R. Evenson, Karin Valentine Goins, Jeanette Gustat, Katie M. Heinrich, Cynthia K. Perry, Michele Scanze, Thomas L. Schmid, Rachel G. Tabak, Renee Umstattd Meyer, and Cheryl Valko provided input into survey questions and study design, provided interpretation of data, and revised the manuscript critically for important intellectual content.

\section{Declaration of Conflicting Interests}

The author(s) declared no potential conflicts of interest with respect to the research, authorship, and/or publication of this article.

\section{Funding}

The author(s) disclosed receipt of the following financial support for the research, authorship, and/or publication of this article:: This work is a product of a Prevention Research Center supported by Cooperative Agreement 1U48DP001946 from the CDC, including the PAPRN.

\section{References}

1. U.S. Department of Health and Human Services. Step It Up! The Surgeon General's Call to Action to Promote Walking and Walkable Communities. Washington, D.C.: U.S. Dept of Health and Human Services, Office of the Surgeon General; 2015.

2. Active Transportation Surveillance-United States, 1999-2012. Am J Public Health. 2016;106(3):e1-e4.

3. Saunders LE, Green JM, Petticrew MP, Steinbach R, Roberts H. What are the health benefits of active travel? A systematic review of trials and cohort studies. PLos One. 2013;8(8):13.

4. Hamer M, Chida Y. Active commuting and cardiovascular risk: a meta-analytic review. Prev Med. 2008;46(1):9-13.

5. Pucher J, Buehler R, Merom D, Bauman A. Walking and cycling in the United States, 2001-2009: evidence from the National Household Travel Surveys. Am J Public Health. 2011;101(suppl 1):S310-S317.

6. Besser LM, Dannenberg AL. Walking to public transit steps to help meet physical activity recommendations. Am J Prev Med. 2005;29(4):273-280.

7. Chriqui JF, Leider J, Thrun E, Nicholson LM, Slater S. Communities on the move: pedestrian-oriented zoning as a facilitator of adult active travel to work in the United States. Front Public Health. 2016;4:71.

8. Beenackers MA, Foster S, Kamphuis C, et al. Taking up cycling after residential relocation: built environment factors. Am J Prev Med. 2012;42(6):610-615.

9. Child ST, Schoffman DE, Kaczynski AT, Forthofer M, Wilcox S, Baruth M. Neighborhood attributes associated with the social environment. Am J Health Promot. 2016;30(8):634-637.

10. Chriqui JF, Leider J, Thrun E, Nicholson LM, Slater SJ. Pedestrian-oriented zoning is associated with reduced income and poverty disparities in adult active travel to work, United States. Prev Med. 2016;95(suppl):S126-S133. 
11. Gustat J, Rice J, Parker KM, Becker AB, Farley TA. Effect of changes to the neighborhood built environment on physical activity in a low-income African American neighborhood. Prev Chronic Dis. 2012;9:E57.

12. Fitzhugh EC, Bassett DR, Evans MF. Urban trails and physical activity a natural experiment. Am J Prev Med. 2010;39(3): 259-262.

13. Merom D, Bauman A, Vita P, Close G. An environmental intervention to promote walking and cycling - the impact of a newly constructed Rail Trail in Western Sydney. Prev Med. 2003;36(2): 235-242.

14. National Physical Activity Plan. National Physical Activity Plan for the United States. Columbia, South America: National Physical Activity Plan; 2010.

15. Healthy People 2020: Topics \& Objectives. Physical Activity. Washington, DC: U.S. Department of Health and Human Services, Office of Disease Prevention and Health Promotion; 2010. https://www.healthypeople.gov/2020/topics-objectives/ topic/physical-activity/objectives. Updated October 18, 2017. Accessed October 18, 2017.

16. Centers for Disease Control and Prevention. State Indicator Report on Physical Activity, 2014. Atlanta, Georgia: U.S. Department of Health and Human Services; 2014.

17. Gase LN, Barragan NC, Simon PA, Jackson RJ, Kuo T. Public awareness of and support for infrastructure changes designed to increase walking and biking in Los Angeles County. Prev Med. 2015;72:70-75.

18. Gustat J, O’Malley K, Hu T, et al. Support for physical activity policies and perceptions of work and neighborhood environments: variance by BMI and activity status at the county and individual levels. Am J Health Promot. 2014;28(3 Suppl):S33-S43.

19. Long MW, Gortmaker SL, Patel AI, Onufrak SJ, Wilking CL, Cradock AL. Public perception of quality and support for required access to drinking water in schools and parks [published online October 3, 2016]. Am J Health Promot. 2016:pii:0890117116671253.

20. Centers for Disease Control and Prevention. Diabetes Interactive Atlases Web Site. http://www.cdc.gov/diabetes/atlas/. Updated May 2, 2017. Accessed April 17, 2013.

21. 2008 Physical Activity Guidelines for Americans. Washington, USA: U.S. Department of Health and Human Services; 2008.

22. Brownson RC, Schmid TL, King AC, et al. Support for policy interventions to increase physical activity in rural Missouri. Am J Health Promot. 1998;12(4):263-266.

23. Cerin E, Saelens BE, Sallis JF, Frank LD. Neighborhood Environment Walkability Scale: validity and development of a short form. Med Sci Sports Exerc. 2006;38(9):10.

24. Centers for Disease Control and Prevention. Behavioral Risk Factor Surveillance System Survey Data. U.S. Department of Health and Human Services, Centers for Disease Control and Prevention. https://www.cdc.gov/brfss/data_documentation/index.htm. Updated August 29, 2017. Accessed March 25, 2014.

25. U.S. Census Bureau. American Community Survey, 2007-2011. https://www.census.gov/acs/www/. Updated August 31, 2017. Accessed June 27, 2013.

26. U. S. Census Bureau. American FactFinder Census 2010. http:// factfinder2.census.gov/faces/nav/jsf/pages/community_ facts.xhtml\#none. Accessed July 26, 2013.

27. United States Department of Agriculture Economic Research Service. Urban Influence Codes. 2013. http://www.ers.usda.gov/ data-products/urban-influence-codes.aspx\#.UzCSCvldX9Y. Updated October 12, 2016. Accessed March 24, 2014.

28. Cradock AL, Troped PJ, Fields B, et al. Factors associated with federal transportation funding for local pedestrian and bicycle programming and facilities. J Public Health Policy. 2009; 30(suppl 1):S38-S72.

29. Sudman S. Applied sampling. New York, NY: Academic Press; 1976.

30. Pucher J, Buehler R, Bassett DR, Dannenberg AL. Walking and cycling to health: a comparative analysis of city, state, and international data. Am J Public Health. 2010;100(10):1986-1992.

31. Resnik DB. Urban sprawl, smart growth, and deliberative democracy. Am J Public Health. 2010;100(10):1852-1856.

32. Reason Foundation/Arthur N. Rupe Foundation. Reason-Rupe Poll: December, 2011. USREASON2011-12, Version 2. NSON Opinion Strategy [producer]. Ithaca, NY: Cornell University, Roper Center for Public Opinion Research, RoperExpress [distributor], https://ropercenter.cornell.edu/CFIDE/cf/action/catalog/ abstract.cfm?type $=\&$ start $=\& \mathrm{id}=\&$ archno $=$ USREASON2011 12\&abstract $=$. Accessed October 18, 2017.

33. Belanger-Gravel A, Gauvin L, Fuller D, Drouin L. Implementing a public bicycle share program: impact on perceptions and support for public policies for active transportation. $J$ Phys Act Health. 2015;12(4):477-482.

34. Dodson EA, Stamatakis KA, Chalifour S, Haire-Joshu D, McBride T, Brownson RC. State legislators' work on public health-related issues: what influences priorities? J Public Health Manag Pract. 2013;19(1):25-29.

35. Alliance for Biking \& Walking. Bicycling \& Walking in the United States: 2016 Benchmarking Report. Washington, USA: Alliance for Biking \& Walking; 2016.

36. Zwald ML, Eyler AA, Goins KV, Brownson RC, Schmid TL, Lemon SC. Understanding municipal officials' involvement in transportation policies supportive of walking and bicycling. $J$ Public Health Manag Pract. 2014;23(4):348-355.

37. Lamb KE, White SR. Categorisation of built environment characteristics: the trouble with tertiles. Int J Behav Nutr Phys Act. 2015;12:8. 